\title{
Dutch set the pace in bid to clean up diet supplements
}

\section{Alison Abbott, Indianapolis}

Nutritional supplements are riddled with contaminants such as steroids and other banned substances, scientists heard at the annual meeting of the American College of Sports Medicine (ACSM) in Indianapolis on 2-5 June. But a new initiative in the Netherlands could serve as a model for countries that want to give their athletes a safer choice, they said.

Supplements contain ingredients such as vitamins, minerals and amino acids. But for several years contaminants have been suspected of causing some athletes to test positive for banned substances, leading authorities to recommend that sportsmen and women stay off them altogether.

A recently published study, conducted at the German Sport University in Cologne, tested 634 supplements bought in 13 different countries between 2000 and 2001 (H. Geyer et al. Int. J. Sports Med. 25, 124-129; 2004). Although their labels claimed they were hormone-free, nearly $15 \%$ of the supplements tested positive for anabolic steroids (see Graph). The authors say that this could be the result of cross-contamination from improperly cleaned machinery, rather than intentional spiking.

In 2002, a study by the Netherlands Centre for Doping Affairs found that nearly a quarter of samples from supplements that Dutch athletes intended to use while training for the Utah Olympic Games were likewise contaminated.

Given that athletes continue to use supplements, several countries have taken steps to catalogue clean sources. Last year, for example, the German Sport University tested 200 supplements approved for medicinal use and found that none contained detectable levels of steroids. "This is clearly down to good manufacturing processes," says Wilhelm Schänzer, head of the Cologne Anti-Doping Institute, who is planning wider studies.

The biggest push to clean up supplements is going on in the Netherlands, the conference was told. The NZVT (Netherlands Security System for Nutritional Supplements in Élite Sports), launched last November, sets manufacturing standards for participating companies - of which there are 25 so far. It then tests each batch of supplement and posts the results online. Random tests are also carried out at later dates. More than 125 batches have been tested so far, all of which are listed on the website as clean.

Scientists at the meeting were impressed by such moves. But they remained concerned that athletes see supplements as performance boosters, despite the lack of evidence for this.
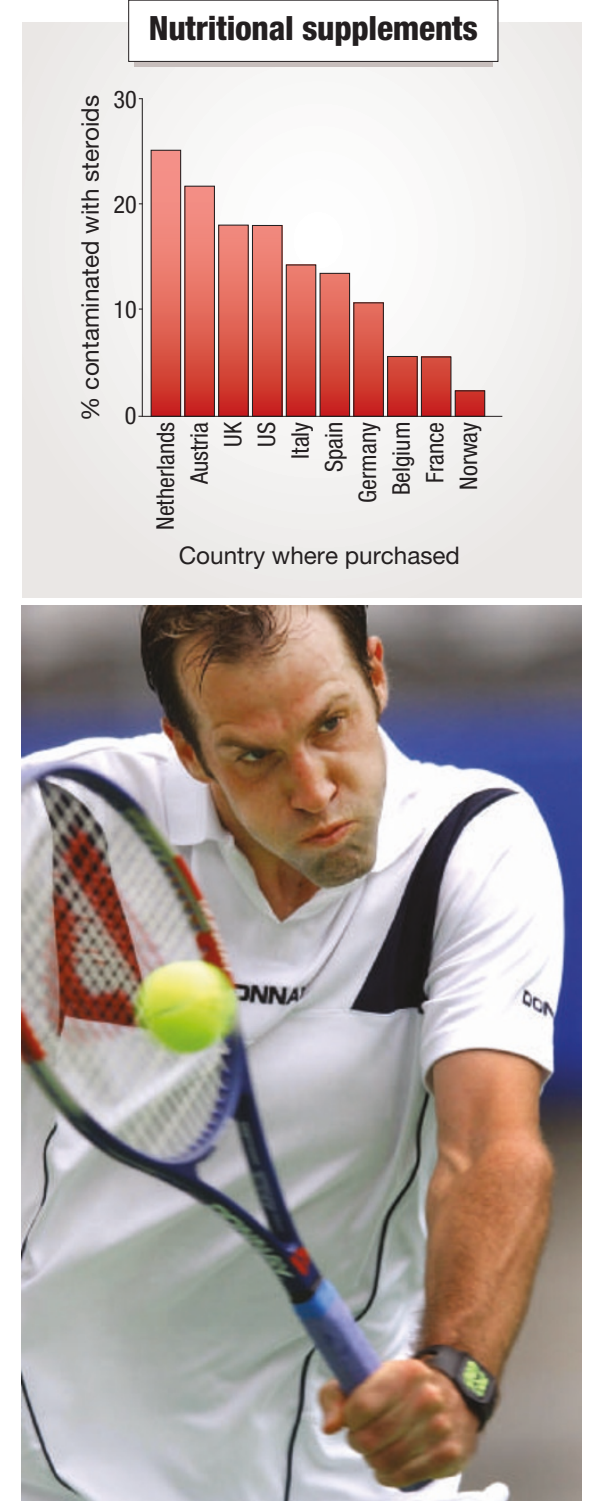

Tennis star Greg Rusedski was cleared of drug charges earlier this year after he said that he had taken contaminated supplements unwittingly.

It has never been proven that supplements do more good for an athlete than a balanced diet, said Ron Maughan, a nutrition expert from the University of Loughborough, UK.

Exercise psychologist James Whitehead from the University of North Dakota, Grand Forks, was one of many who complained that some exhibitors at the meeting were pushing supplements. "It has been a problem here for years," he said. Karl Fischer, who will soon become president of the ACSM, said that the claims of advertisers are checked by the college for sexism and slander but not for scientific content. "But this will change," he promised.

www.necedo.nl
Genomics institute rejects Venter's streamlining plan

Erika Check, Washington

Chiefs at The Institute for Genomic Research (TIGR) in Rockville, Maryland, and affiliated organizations led by bioentrepeneur Craig Venter have rejected a plan to consolidate their workforces - at least for now.

Venter co-founded TIGR with his wife, Claire Fraser, in 1992. In 2002, he started three other organizations using funding from the J. Craig Venter Science Foundation: the Institute for Biological Energy Alternatives, the Joint Technology Center and the Center for the Advancement of Genomics. TIGR is partly funded by the foundation, but it also receives money from outside sources such as the National Institutes of Health.

Earlier this year Venter proposed combining the workforces of all of these organizations. "We have five not-forprofit organizations and five boards and we have duplicate human resources, finance and other departments, and it's been draining the money that comes out of the foundation," Venter says.

Venter is chairman of TIGR's board, whose membership overlaps with those of the foundation and the other institutes. Fraser has directed TIGR for the past six years. But there are concerns that the present set up might lead to tension because Fraser and Venter, who have been married since 1981, are now separated.

Venter says that this did not influence his decision to seek consolidation. "Both myself and the board have been very supportive of her job," he says of Fraser.

Late last month, TIGR's board decided to keep the institute separate from the other three organizations, which will merge into a single entity. "TIGR really has a different style and mission from the other organizations," says Gerald Rubin a TIGR board member and vice-president of the Howard Hughes Medical Institute in Chevy Chase, Maryland.

But Venter did not rule our future reorganizations. "Nothing is ever final," he says.

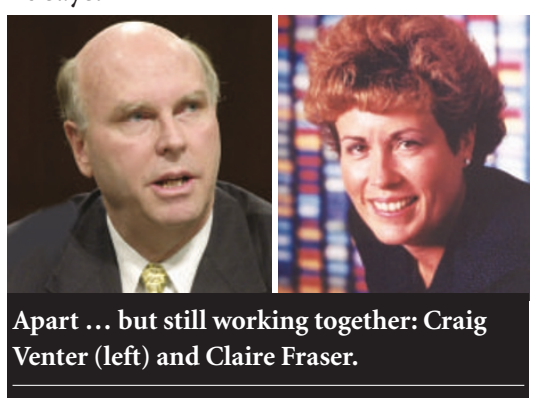

